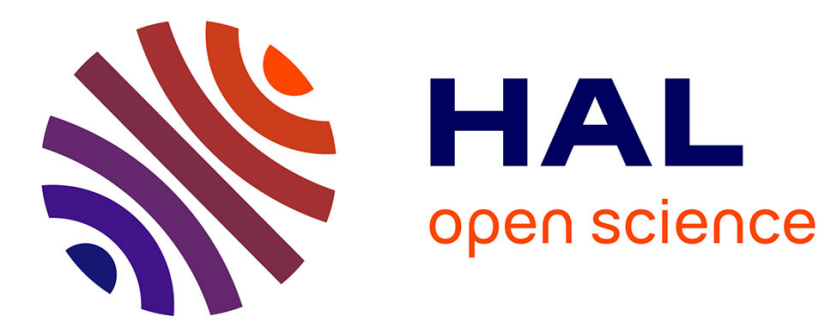

\title{
Beyond "decorative" 2D supramolecular self-assembly: strategies towards functional surfaces for nanotechnology
}

Lydia Sosa-Vargas, Eunkyoung Kim, André-Jean Attias

\section{To cite this version:}

Lydia Sosa-Vargas, Eunkyoung Kim, André-Jean Attias. Beyond "decorative" 2D supramolecular self-assembly: strategies towards functional surfaces for nanotechnology. Materials Horizons, 2017, 4 (4), pp.570 - 583. 10.1039/C7MH00127D . hal-01563958

\section{HAL Id: hal-01563958 \\ https://hal.sorbonne-universite.fr/hal-01563958}

Submitted on 18 Jul 2017

HAL is a multi-disciplinary open access archive for the deposit and dissemination of scientific research documents, whether they are published or not. The documents may come from teaching and research institutions in France or abroad, or from public or private research centers.
L'archive ouverte pluridisciplinaire HAL, est destinée au dépôt et à la diffusion de documents scientifiques de niveau recherche, publiés ou non, émanant des établissements d'enseignement et de recherche français ou étrangers, des laboratoires publics ou privés. 


\title{
Journal Name
}

\section{ARTICLE}

\section{Beyond "decorative" 2D supramolecular self-assembly: strategies towards functional surfaces for Nanotechnology}

\begin{abstract}
Lydia Sosa-Vargas, ${ }^{a}$ Eunkyoung Kim, ${ }^{\text {and André-Jean Attias }}{ }^{* a}$
2D supramolecular self-assembly has emerged as a powerful tool in nanoscience for bottom-up fabrication of well-defined and long range ordered two-dimensional (2D) molecular nanostructures at surfaces. Following an overview of the principles of this distinctive self-assembly process, this review focusses on recent stategies developed to go beyond the surface nanopatterning and to provide functional surfaces. With an emphasis on the chemical engineering of the molecular building-blocks constituting the adlayer, we show that besides supported nanoporous networks the more promising approach lies on up-standing 3D functional build-blocks mounted on the substrate. We highlight the opportunities offered by graphene, a substrate for which the non-covalent functionalization by supramolecular selfassembly represents a way to either control its electronic properties or provide it a new functionality. Finally, future perspectives are addressed.
\end{abstract}

\section{Introduction}

Supramolecular self-assembly at surfaces, so-called twodimensional (2D) supramolecular self-assembly, has emerged has a powerful tool in nanoscience for bottom-up fabrication of well-defined and long range ordered 2D molecular nanostructures at surfaces. ${ }^{1-2}$ This approach aims to create a tailored interface, which is assembled molecule by molecule to produce in a parallel process a supramolecular architecture and to alter the surface properties. Much of the work in surface-confined supramolecular self-assembly has focused on the understanding of this distinctive self-assembly process and on the engineering principles, leading to the well-mastered patterning of substrates. The next step recently developed to go beyond the decorative supramolecular self-assembly at surfaces is to provide a functionality to the whole 'substrateorganic adlayer' hybrid system. Such surface engineering is of paramount importance to functionalize substrates at the nanometer scale in view of potential applications in emerging fields such as molecular spintronics, molecular rotors, sensing or molecular and organic electronics.

In this review, we summarize the different strategies towards functional surfaces by supramolecular self-assembly in scope of their applications within nanotechnology. With this aim, we present the issues that arise within each approach, with an emphasis on the chemical engineering of the

\footnotetext{
a. Institut Parisien de Chimie Moléculaire, UMR CNRS 8232, Sorbonne Universités, Université Pierre et Marie Curie, 4 place Jussieu, 75252 Paris Cedex, France. Email : andre-jean.attias@upmc.fr

b. Department of Chemical and Biomolecular Engineering, Yonsei University, 50 Yonsei-ro, Seodaemun-gu, Seoul 120-749, South Korea
}

molecular building-blocks. First, we start with a brief overview of the background and current state of the art of supramolecular self-assembly at surfaces. Afterwards, according to the main objective of this review we briefly examine functional systems (nanoporous networks) where the collective properties originate from the supramolecular selfassembly itself, and are not present in the individual molecular components. Since most studies have focused on 2D structures, we show that an additional complexity has to be incorporated in the surface normal direction, the third $\left(3^{\text {rd }}\right)$ dimension. Thus, we describe some examples where 3D molecular building blocks, functional by themselves, are adsorbed on the surface. In the last part, we address the present popularity of graphene and its use as a highly desirable substrate for functionalization, examining some of the ongoing research in relation to its modification by the supramolecular approach. Lastly, we conclude by examining and discussing future perspectives of a new generation of functional surfaces, transcending from molecular-level systems into the nanoscale and leading to a realistic development of functional nanomaterials.

\section{Principles of supramolecular self-assembly at surfaces}

Supramolecular self-assembly at surfaces is a multidisciplinary approach based, in a first key step, on the chemical engineering of molecular building-blocks (tectons). They consist in mostly planar extended $\pi$-systems equipped with peripheral functional groups able to engage in non-covalent interactions such as hydrogen bonding, metal-ligand, and van der Waals interactions. In a second step, the specifically designed tectons are adsorbed on the substrate, diffused on it, 
and their non-covalent coupling leads to the formation of physisorbed well-ordered 2D supramolecular adlayers. The molecular layers can be formed either under ultra-high vacuum (UHV) conditions at the UHV-solid interface or under ambient conditions at the liquid-solid interface. In the former case, the substrate can be an atomically flat metal or semiconductor. Under ambient conditions, besides Au (111), highly oriented pyrolytic graphite (HOPG) is the most commonly used substrate due to its stability. Recently, another $\mathrm{sp}^{2}$-hybridized carbon substrate, graphene, has received a growing attention driven by the current interest in its non-covalent functionalization. Besides graphene, other 2D substrates have also been used such as hexagonal boron nitride (h-BN) or transition metal dichalcogenides (e.g. $\mathrm{MoS}_{2}$ ). These surface-confined nanostructures are studied by using scanning probe microscopies (SPMs), and in particular scanning tunnelling microscopy (STM) and spectroscopy (STS). Indeed, these tools enable the characterization in direct space and at atomic-scale in terms of topography and spectroscopy, giving a deep insight into the organization and electronic interactions occurring within.

Following the seminal work of Foster et al. ${ }^{3}$ and Rabe et al.., ${ }^{4}$ a great diversity of supramolecular self-assembled onedimensional (1D) and two-dimensional (2D) structures resulting from the surface deposition of a huge number of molecular building-blocks were observed. After extensive work published on the description and a posteriori empirical interpretation of nanostructure organization on surfaces, numerous studies were devoted to the understanding of the mechanisms and parameters driving the surface-confined supramolecular self-assembly. The structure of the adlayer obtained by 2D supramolecular chemistry, the so-called noncovalent synthesis at surfaces, arises from a subtle and fine balance between the molecule-substrate and the moleculemolecule lateral interactions (Figure 1). The main highlighted characteristics are the structure of the elemental building blocks in terms of the core unit shape and number as well as the position of the peripheral chemical functionalities directing the self-assembly on the one hand, and the type of surface on the other. Moreover, at the liquid-solid interface; the type of solvent, the concentration of the tecton, and the temperature also influence the self-assembling processes. All those results have been subject to published reviews and have allowed the 'decoration' of surfaces with mono-, multicomponent, and hierarchical well-defined 2D networks (Figure 2). ${ }^{5-13}$

\section{Strategies towards functional surfaces}

To go beyond the above mastered decorative surface-confined supramolecular self-assembly, the next step is the development of functional surfaces, the ultimate goal being their integration into functional (nano)devices.

\section{a) 2D nanoporous networks}

In this regard, alveolate 2D networks (controllable both in pore size/shape and pore to pore distance) should be of particular interest due to their capability to act as host-guest systems.
Since these nanoporous networks expose well-defined voids (diameter of a few nanometers) they can be used as templates capable of trapping or releasing guest molecules. ${ }^{14-16}$ In most of the cases of host-guest recognition, the host template plays the role of a sieve and the guest molecules accommodate themselves within the voids. In order to tune the guest binding ability of porous networks, sophisticated approaches have been developed to functionalize the pores. ${ }^{17-19}$ Besides simple passive occupation of the cavities by the guest molecules, their rotational and lateral mobility inside a cavity, and their hopping between cavities has been evidenced. ${ }^{20-23}$ On the other hand, taking advantage of the dynamic character of the supramolecular chemistry, strategies have been developed to transform a linear nonporous two-dimensional network into a honeycomb porous network in response to the addition of guest molecules. ${ }^{24-25}$ All these works represent the first steps towards functional systems by addressing various interesting issues such as guest selection, recognition, immobilization and dynamics. However, so far, all these features remain confined within the plane, precluding any applications.

Therefore, one critical challenge is to exploit the room above the substrate i.e. the $3^{\text {rd }}$ direction perpendicular to the substrate. This is mandatory for the progress of for example electronics and photonics, in which the proximity of adsorbed photoactive units with conducting substrates results in a fast quenching of the electronic excitation. Access to the 3rd dimension is also needed to introduce rotary motions or to fabricate functional bio-interfaces. Therefore, providing approaches for the incorporation of a 'functional' moiety positioned atop the surface is a prerequisite. The first approach and also the most popular and highly developed method -self-assembled monolayers (SAMs) ${ }^{26-27}$ is based on the chemisorption of building-blocks on (semi-)conductor and dielectrics surfaces. The self-assembling molecule consists of a head group that binds to the substrate, a spacer chain (tilted approximatively $30^{\circ}$ from the vertical), and a functional tail group. SAMs, mostly thiol derivatives on gold, have emerged as versatile platforms for generating exposed surfaces since exhibiting a wide range of well-defined functionalities (nonpolar, polar, electroactive, hydrogen bonding etc...). Thus, SAMs can find applications in numerous fields such as organic electronics. ${ }^{28}$ However, this approach suffers from the poor control of the lateral order offered by functionalized SAMs. Indeed, if the tail group is large relative to the cross-sectional area of the spacer alkane chain $(0.184 \mathrm{~nm} 2)$ the intralayer organization is disordered. ${ }^{26}$ To tackle this issue, multipodal platforms bearing several anchoring groups to increase the binding stability as well as the footprint have been developed. ${ }^{29}$ Moreover the SAM based strategy cannot be used for the functionalization of carbon allotropes such as carbon nanotubes, HOPG, and graphene. Besides the above SAM based approach, during the last decade considerable effort has been devoted to extend supramolecular selfassembly at surfaces (by physisorption through non-covalent chemistry) into the direction perpendicular to the surface, in order to add a function which mustn't disturb the 2D selfassembly and be preserved from possibly-detrimental 
substrate influences. The main goal of this critical review is to present the strategies developed for functional up-standing 3D build-blocks in the literature.

The use of nanoporous 2D networks can be exploited further for trapping 3D guests to build non-planar networks, towards 3D surface-based supramolecular architectures. ${ }^{30}$ One example of this type of template is a hydrogen-bonded monolayer based on p-terphenyl-3,5,3",5"-tetracarbocylic acid (TPTC) self-assembled on HOPG. After addition of $\mathrm{C}_{60}$ molecules, STM shows not only the adsorption of the 3D guests into the pores of the monolayer but also the formation of a second nanoporous layer of TPTC molecules, selfassembled around the spherical shaped $C_{60}$ molecules. This is an example of guest-induced growth into the dimension perpendicular to the substrate, the $\mathrm{C}_{60}$-bilayer network consisting of two overlying pores. Moreover, the subsequent addition of a planar guest molecule (coronene) leads to the removal of $C_{60}$, with the $C_{60}$-bilayer network being replaced by a TPTC monolayer porous network with coronene immobilized within. Thus, the authors have demonstrated the reversible transformation between a single-layer and a bilayer structure induced by the guest. In this case, whilst a " $3 D^{\prime}$ " system is achieved, it is not truly "functional" as we cannot exploit the molecular properties of the guests $\left(C_{60}\right)$ due of the electronic coupling that exists with the substrate.

\section{b) 3D functional tectons}

Another approach consists in self-assembling 3D functional tectons. With this aim, several strategies have been developed.

Phthalocyanine $(\mathrm{Pc})$ materials have proved to be popular molecular species for supramolecular assembly on various metallic/ non-metal substrates, being capable to form a diverse variety of highly-ordered, long-range, surface-confined 2D-monolayers. ${ }^{31}$ Pcs can also be used to project into the 3rd dimension by the formation of 3D functional building blocks consisting of a lanthanide cation (Ln) sandwiched between two Pc ligands (Figures $3 a$ and $b$ ). These mononuclear metal complexes $\left(\mathrm{LnPc}_{2}\right)$ have demonstrated magnetic behavior, as single molecular magnets $(\mathrm{SMMs}) .^{32}$ More complex multidecker phthalocyanine complexes $\left(\operatorname{Ln}_{x} \mathrm{PC}_{\mathrm{x}+1}\right)$ have also been synthesized. These lanthanide double-decker Pc complexes play a key role in molecular spintronics due to their exceptional robustness when confined to a surface. In particular, the magnetic properties of $\mathrm{TbPc}_{2} \mathrm{SMMs}$ have been studied thoroughly whilst deposited on various metallic, $\mathrm{sp}^{2}$. hybridized and insulating substrates. These studies have provided insight into how the magnetic properties can be affected in relation to the Pc-surface interactions, ${ }^{33}$ thus paving the path for potential implementation of these materials in functional nanodevices. ${ }^{34}$ On the other hand, when adsorbed on $\mathrm{Au}(111)$ in UHV at low temperatures, $\left(\mathrm{TbPc}_{2}\right)$ exhibits two adsorption configurations, due to an azimuthal rotational angle between the two facing Pc ligands. It was demonstrated that the rotation of the Pc ligands can be monitored by applying a pulse with the STM tip. Since this electric driven molecular switching effect modifies the molecular spin density, information (bit) can be encoded at the molecular level (Figure 3c). A similar sandwich approach to extend supramolecular assemblies at surfaces into the $3^{\text {rd }}$ dimension has been carried out with tetraphenylporphyrin (TTP) leading to multi-decker porphyrin systems. ${ }^{35}$ Cerium double and triple decker complexes have been synthesized. The main feature of these systems when adsorbed on Ag (111) in UHV at low temperatures is the rotational motion of the upper porphyrin by STM manipulation. In all the above examples, the functionality of the 3D building blocks mounted on the surface is evidenced solely by addressing the individual molecules.

Other types of 3D tectons architectures have been developed for applications in photonics and organic electronics where the functional moiety of the molecular tecton must be decoupled from the conducting substrate (Figure 4). The simplest class of molecules developed to ensure this, are the so-called 'molecular landers' (Figure 4a). ${ }^{36}$ They comprise a central polyaromatic and rigid molecular main board (molecular wire) linked to several bulky side-groups acting as spacer legs. When the molecular landers are adsorbed on a metallic surface, the spacers maintain the main board at such a distance from the surface that the aromatic part becomes electronically decoupled from the surface. Designed without a specific functional group for lateral interactions, the landers adsorbed on a substrate do not form long-range ordered patterns. However, manipulated individually they exhibit interesting properties for molecular electronics. More interestingly, they are able to trap metal atoms and act as moulds for metallic nanostructures. Therefore, building 2D long-range ordered nanostructures could allow the formation of metallic nanostructures. With this aim, a lander molecule was for the first time equipped with a functional moiety, the diamino-triazine (DAT), which enabled intermolecular hydrogen bonding interactions. ${ }^{37}$ On Au (111), under UHV conditions, at low temperatures, 1-D chains and 2-D patterns were observed and their formation explained through molecular mechanics modelling. More recently, the coadsorption of two molecular landers equipped with complementary hydrogen bonding motifs have been investigated. $^{38}$

Another strategy used for surface decoupling, consists of assembling functional, multi-story tectons. With this in mind, the cyclophane species consisting of two identical planar piconjugated disks arranged face-to-face are attractive structures. As a first example, Watson et al. investigated alkylsubstituted hexa-peri-hexabenzocoronene cyclophane derivatives assembled on HOPG under ambient conditions. ${ }^{39}$ They demonstrated the feasibility of STM and STS studies of 3D molecules lying flat on the substrate. The STS results revealed a diode-like behavior, making these 3D tectons potential components for single molecule electronics. Matino et al. also demonstrated the advantage of a cyclophane structure for the electronic decoupling of an organic chromophore from a metal substrate, e.g. Au (111). ${ }^{40}$ They investigated a naphthalene diimide (NDI) cyclophane consisting of two NDI chromophores from which only one can 
adsorb to the surface, whilst the second one is expected to remain separated from the metal (Figure 4b). STM images recorded under UHV conditions at low temperatures, confirm the expected face-on organization on the substrate and STS studies demonstrate the effectiveness of the spatially electronic decoupling from observations of vibronic excitations. Thanks to this decoupling, a scanning tunnelling microscope was used to induce light emission, by injecting electrons from the tip to the sample. ${ }^{41}$ We should note that in all these examples the properties observed come solely from the individual molecules and their structural composition lacks some versatility.

Consequently, a different approach can be followed, based on customizable molecular 3D tectons in order to ensure the structural versatility in terms of chemical engineering.

With this objective, Bléger et al. developed 3D tectons consisting of two faces linked by a spacer (pillar), applying the so-called Janus tecton concept (Figure 4c). ${ }^{42}$ One face, the "pedestal", is designed to steer 2D self-assembly onto $\mathrm{sp}^{2}$ carbon-based flat surfaces and the other allowing for the desired functionality to be incorporated above the substrate thanks to the pillar, with a well-controlled lateral order. The Janus tecton construction method uses [2.2]paracyclophane derivatives as pillar, where the lower-deck of the pillar is connected to two binding units specifically designed for steering the supramolecular self-assembly on graphitic substrates (clip) and the upper-deck of the pillar allows the attachment of the functional unit. As shown by STM studies at liquid-HOPG interface, this design leads to the self-assembly of 3D tectons building-up perpendicular to the substrate. The pedestal lies flat on the surface paving the HOPG with longrange ordering and controlling the organization of the superjacent functional units, hence leading to a periodic array of e.g. chromophores at a defined distance from the substrate. Du et al. took advantage of the cyclophane chemistry to build a multi-story pillar that allows the tuning of the distance between the functional unit and the substrate. ${ }^{43}$ This highly versatile approach allows through the modification of the upper-face, for the preparation of a wide range of 3D Janus tectons that expose various functional units ranging from fluorophores to functional moieties for potential uses, such as for hydrogen- bonding, metal-ligand bonding, and redox processes. ${ }^{44}$ The effectiveness of the electronic decoupling will be evidenced in part 3.d. by using a chromophore as functional unit.

A second example of 3D-building blocks that also displays great versatility is based on the "platform" concept, specifically developed to work on gold substrates (Figure $4 d$ ). Baish et al., responsible for the introduction of this concept, developed a modular system consisting of a platform, a spacer, and a functional unit. ${ }^{45}$ More specifically, the platforms used are based on triazatriangulenium (TATA) ions, whereas ethynyl units are used as spacers to attach the target functional molecule to the TATA. The TATA platforms are functionalized vertically at the center and provide modular systems that form well-ordered 2D networks on Au (111), as evidenced by STM at the air-solid interface at room temperature. The platforms lie flat on the substrate, whilst the spacer and the functional unit are oriented perpendicular to the surface. The size of the platform, determined by the size of the peripheral substituents, controls the distance between the neighbors on the surface and therefore the spacing between the functional groups, whereas the length of the spacer defines their distance from the surface. The versatility of this approach was evidenced by immobilizing functional molecules such as azobenzenes and porphyrins. ${ }^{46-48}$ The electronic decoupling of these systems was demonstrated by studying the photo-and thermally induced switching of azobenzene-functionalized TATA platforms, under ambient conditions. ${ }^{49}$ The main result is that the azobenzenes mounted on platforms exhibit fast, reversible, and reproducible photoisomerization demonstrating that the electronic properties of the azobenzene functionality are preserved. The photoisomerization is possible because the platform provides sufficient space for the switching between the cis-trans azobenzene conformers. Moreover, in the case of porphyrin as functional unit, it was demonstrated that the ethynyl unit can act as a pivot joint. If the distance between the platform centers is larger or smaller than the porphyrin diameter, the free azimuthal rotation is observed or locked, respectively.

As an alternative mode, the porphyrin unit can also function as the molecular platform. Feringa and coworkers have recently shown that metal-organic interactions using porphyrins can be exploited to achieve 3D-architectures by the bottom up approach (Figure 4e). ${ }^{50}$ This method of functionalization has the potential to create a variety of "functional surfaces" by coordinating a surface-confined Pc or porphyrin to any pyridine or amine ligand bearing any desired functionality. This strategy has been widely used when synthesizing supramolecular Pc-based donor-acceptor ensembles, ${ }^{51}$ on non-confined systems and therefore offers us a practical route in which the highly-versatile Pc or Por unit can be used.

\section{Graphene, the rising star in nanomaterials: a substrate plus a component for supramolecular self-assembly}

Graphene has attracted intense research activities in recent years due to its unique and outstanding properties, ${ }^{52-53}$ such as superlative mechanical strength, high optical transparency, extremely high conductivity and carrier mobility, and the absence of a bandgap. All these features make graphene a promising material for photonics and electronic applications. ${ }^{54}$ Pristine graphene is a network of $\mathrm{sp}^{2}$-hybridized carbon atoms packed into a 2D honeycomb lattice, and as a one-atom-thick material, its surface and bulk coincide. Thus, the adsorption of molecules can not only provide a new functionality (e.g. improved solubility or bio-selectivity) but also modulate graphene intrinsic electronic properties. The covalent attachment of molecules to the graphene basal plane involves the conversion of $\mathrm{sp}^{2}$ carbon atoms into $\mathrm{sp} 3$ ones. Such covalent bond-forming chemistry modifies the periodicity of 
the graphene network and thereby introducing a band gap, ${ }^{51}$ but this also leads to the destruction of the basic electronic properties of graphene, such as the high carrier mobility. For this reason, non-covalent functionalization by physisorption of molecules has emerged as a promising strategy manipulate graphene electronic properties, ${ }^{56-58}$ by induced interfacial charge transfer (electrons or holes) between organic molecules and graphene. This process is driven by the position of the highest occupied molecular orbital (HOMO) and the lowest unoccupied molecular orbital (LUMO) of the adsorbed molecule and the Fermi level of pristine graphene $(\sim 4 \mathrm{eV})$ (Figure 5). ${ }^{59-60}$ Adsorption of $\pi$-conjugated molecules with HOMO lying above the graphene Fermi level will induce a transfer from the molecule to the graphene (electron-donor molecule), leading to n-type doping. For molecules with a LUMO lying bellow the graphene Fermi level the transfer occurs from graphene to molecule (electron-acceptor molecule), leading to a p-type doping. Raman spectroscopy is the method of choice to monitor the doping in graphene. ${ }^{61}$ It has been demonstrated that a tailored molecular doping allows the control of charge carrier type and concentration and can generate a band gap, ${ }^{62}$ prerequisites for electronic applications. The electron-acceptor organic molecules reported include: 2,3,5,6-tetrafluorotetracyanoquinodimethane (F4-TCNQ), perylene-3,4,9,10tetracarboxylic-3,4,9,10-diimide (PTCDI), perylene-3,4,9,10tetracarboxylic-3,4,9,10-dianhydride (PTCDA), and tetracyanoethylene (TCNE), whereas tetrathiofulvalene (TTF) is used as an electro-donating molecule. More recently, organometallic complexes have also been successfully used ${ }^{63-}$ 64

\section{a) "Decorative" supramolecular self-assembly on graphene}

Since graphene can be viewed as the last sheet of graphite (HOPG) - a 3D stack of graphene sheets itself-, the comparison of the supramolecular self-assembly processes on these both $\mathrm{sp}^{2}$-hybridized carbon substrates was investigated. It was shown that in some cases, depending on graphene growing process, it is a functional substrate in that it directs the selfassembly.

In the early works, the investigated molecules were mostly commercially available ones, and previously known for their assembly on HOPG, these ranged from PTCDA, ${ }^{65-66}$ metallophthalocyanines, ${ }^{67-72} \mathrm{C}_{60},{ }^{73-75} \mathrm{TCNQ}$, and F4-TCNQ. ${ }^{76}$ Experiments for their study are usually performed under UHV mostly at low temperatures, where the molecules are deposited via thermal evaporation after in-situ growth of the graphene layer. The self-assembly of organic molecules on graphene is always achieved using single layers supported by a substrate on which it was either grown or transferred. When graphene is epitaxially grown on metal single crystal, lattice mismatch between graphene and underlying substrate leads to a superlattice called Moiré pattern. This later induces a modulation of the carbon electronic properties, depending on their position with regard to the surface metal atoms. It was experimentally and theoretically demonstrated that different self-assembling behaviors occur depending on the type of graphene-substrate interactions, as reviewed by Kumar et al. ${ }^{77}$ For graphene growth by chemical vapor deposition (CVD) on $\mathrm{Ru}(0001)$ crystal, the superlattice leads to site-selective adsorption which strongly affects the molecular physisorption and consequently the formation of the molecular network. This suggests that molecule-substrate interactions dominate over intermolecular interactions. Taking advantage of this feature and going beyond the observation of the organic adlayer self-assembly, Zhang et al. showed that Kagome lattice of iron phthalocyanine formed on such graphene monolayer can be employed as host template for guest molecules leading to host-guest molecular superstructures. ${ }^{78}$ Lu et al. also demonstrated that the site-selective adsorption allows the template and hierarchy assembly of $\mathrm{C}_{60}$ molecules. ${ }^{79}$ Similarly, Pollard et al. have shown that graphene grown on $\mathrm{Rh}$ (111) can act as a template for the formation of hierarchical selfassembled PTCDI-based nanostructures. ${ }^{80}$ On the contrary, when graphene-substrate interactions are weaker, like for graphene epitaxialy CVD grown on $\mathrm{Pt}(111), \operatorname{Ir}(111), \mathrm{Cu}$ or grown by silicon thermal sublimation from $\mathrm{SiC}(0001)$ substrate on the one hand or for graphene reported onto a substrate (mica, $\mathrm{SiO}_{2}, \mathrm{~h}-\mathrm{BN}$ ) on the other hand, HOPG-like selfassembled nanostructures are observed. For example, Wang et al. achieved the self-assembly of PTCDA on epitaxial graphene grown on the $\mathrm{SiC}(0001)$ surface. ${ }^{81}$ After deposition in UHV, STM images reveal that a well-ordered self-assembled monolayer is formed, sweeping the graphene defects. The observed herringbone arrangement of the monolayer resembles that seen on HOPG. Therefore, in these molecular adlayers, molecule-molecule interactions dominate over molecule-substrate interactions. More recently, the realization of more complex multicomponent systems as on HOPG was demonstrated by Banerjee et $a l^{82}$ First, from 1,3,5benzenetribenzoic acid (BTB) the formation of nanoporous networks self-assembled by hydrogen bonds on graphene on Ir(111) was observed under UHV conditions. In a second instance, these nanopores were then used as a template to host cobalt phthlaocyanine (CoPc) guest molecules.

Although the liquid-solid interface is the most popular for studying self-assembly processes and nanostructures on HOPG under ambient conditions, this alternative process to UHV was only recently explored. Li et al. have translated the molecular engineering rules working on HOPG to graphene and selfassembled a dehydrobenzo[12]annulene (DBA) derivative equipped with long alkyl chains containing diacetylene units on graphene supported on different substrates (graphene epitaxialy grown on $\mathrm{SiC}, \mathrm{CVD}$-grown graphene on $\mathrm{Cu}$, exfoliated graphene on mica). ${ }^{83}$ STM and AFM investigations first reveal that robust, air-stable, self-assembled honeycomb nanoporous networks are formed. Secondly, the networks appear to follow the topography of the graphene surface whatever its roughness, and similar to HOPG, the supramolecular self-assembly is stabilized by van der Waals interactions between interdigitated alkyl chains.

As we can see, the non-covalent, supramolecular approach for surface functionalization, specifically in graphenoid substrates has proven quite successful. ${ }^{84-86}$ Nonetheless, this 
strategy still presents some issues as there are only limited examples of surface functionalization that do not interact with the electronic properties of the substrate (graphene) and secondly, where the long-range order of these surface confined 2D-arrays can be incorporated into higher order nanostructures.

\section{b) Towards functionality: tuning the bandgap}

With this aim, Prado et al. have demonstrated the graphene $\mathrm{p}$ doping under ambient conditions through non-covalent functionalization with phosphonic acid. ${ }^{87}$ The octadecylphosphonic acid (OPA), where the phosphonic acid headgroup -electron acceptor- is attached to a long and linear alkyl chain, was deposited by drop-casting onto exfoliated graphene flakes onto $\mathrm{SiO}_{2}$ layer covering a p-doped $\mathrm{Si}$ substrate. It was demonstrated experimentally by AFM characterization and in combination with theoretical calculations that well-organized monolayers can be formed on graphene in a similar fashion as to HOPG. These monolayers consist of phosphonic acid dimers where the alkyl chains are oriented along the graphene in a perfect zigzag-type alignment with the underlying layer. They also reported the occurrence of charge transfer between graphene and the organic adlayer, investigated by Raman spectroscopy and ab initio calculations. In the Raman spectra, the adlayer was found to a shift of the graphene $\mathrm{G}$ peak to higher wavenumbers with a reduction of its width, and the decrease of the relative intensity of the second-order graphene $2 \mathrm{D}$ peak in relation to the $\mathrm{G}$ peak. In this case the charge-carrier concentration, being estimated to $1.2 \times 10^{13} \mathrm{~cm}^{-2}$ is in agreement with the value predicted by theoretical calculations $\left(5.3 \times 10^{13} \mathrm{~cm}^{-2}\right)$. However, it must be noticed that in this case, the graphene was already slightly doped before OPA deposition $\left(0.2 \times 10^{13} \mathrm{~cm}^{-2}\right)$.

In another example, $\mathrm{Li}$ et al. have self-assembled oleylamine (OA) from a spin-coated solution under ambient conditions, to n-dope epitaxial graphene on $\mathrm{SiC}^{88}$ In this work, the $\mathrm{NH}_{2}$ group is expected to potentially act as an electron donor and the long alkyl chain should steer the self-assembly. First, AFM and STM images after deposition of OA on both HOPG and graphene were recorded, showing that homogeneous self-assembled monolayers consisting of ordered nanostripes are formed whatever the substrate. The relative orientation along three preferred directions reflecting the three-fold symmetry of the $\mathrm{sp}^{2}$ carbon-based underlying surfaces suggest an epitaxial arrangement on both substrates. A tentative model of the organization within the lamellae was proposed: the molecules adopt a head-to-head noninterdigitated configuration forming dimers perpendicular to the lamellar direction, and the alkyl chains lie parallel on the basal plane of the substrate. Second, the modifications of the electronic properties of graphene were investigated by electrical characterization of a backed-gated graphene field effect transistor (GFET). The transfer characteristics show a shift of the charge neutrality point (CNP) to negative voltages, consistent with electron accumulation in the graphene channel, i.e. $n$-doping. The VPN values reached $-16 \mathrm{~V}$ and $-28 \mathrm{~V}$ after a first and second deposition of OA, respectively. Thus, by varying the $\mathrm{OA}$ deposition conditions, the maximum estimated electron doping concentration reached a value of $7.7 \times 10^{12}$ $\mathrm{cm}^{-2}$.

More recently, Feringa and coworkers investigated the electronic properties of commercially available graphene reported on silicon/silicon dioxide modified by self-assembled bis-urea-terthiophene based molecules. ${ }^{89}$ The STM images at the liquid/solid interface at room temperature indicate that well-ordered nanostructures are formed, the hydrogen bonds driving the formation of one-dimensional molecular wires in which the thiophene cores form wires separated by the same well-defined spacing distance on both HOPG and graphene substrates. In order to study the effect of the non-covalent functionalization of graphene on its electrical properties, several large-area transistors have been prepared. The authors observed changes in doping levels and variation in charge carrier mobility, however they demonstrate that doping levels are uncontrolled and weak compared to the effect of unwanted dopants. In all the above examples, the weakness lies in the lack of molecular design to adapt the frontier orbitals of the molecular tecton to control the charge transfer.

Bandgap opening by patterning graphene was also demonstrated by Yang et al., ${ }^{90}$ through STM and STS studies of a self-assembled monolayer of a PTCDI derivative on epitaxial graphene on hexagonal silicon carbide - SiC(0001). The STM images evidence the existence of six types of molecular orientations of the adlayer in respect to the substrate. STS results show that the interaction between the PTCDI molecules and the graphene surface shifts the LUMO towards the Fermi level, inducing a charge transfer and thus contribute to the opening of a band gap in the graphene.

\section{c) Off-plane functionalities}

The need to access the $3^{\text {rd }}$ dimension to decouple from graphene molecules exhibiting optical properties was evidenced by several works. Kozhemyakina et al. have indirectly demonstrated by Raman spectroscopy the quenching of fluorescence of perylene bisimide (PBI) derivatives adsorbed on graphene. ${ }^{91}$ At $532 \mathrm{~nm}$ excitation, both graphene peaks (D, G, and $2 \mathrm{D}$ bands) and peaks originating from the $\mathrm{PBI}$ are observed, although this molecule is strongly fluorescent when resonantly exited at this wavelength, usually precluding to measure a Raman spectrum of the pristine dye. Thus, the above result is consistent with an efficient fluorescence quenching of perylene by graphene. This feature is associated with photo-induced electron transfer (Dexter process). Moreover, Wojcik et al. probed the excited electron-transfer interaction by studying fluorescence lifetime of porphyrin on graphene. ${ }^{92}$ On the other hand, quenching of fluorescence can also be due to a nonradiative energy transfer to graphene (Förster process). Gaudreau et al. evidenced this process by measuring emitter (Rhodamine) lifetimes as a function of emitter-graphene distance $d .^{93}$ The separation between Rhodamine and graphene is tuned by depositing $\mathrm{TiO}_{2}$ spacer layer of controlled thickness. The observed energy transfer rate is proportional to $d^{-4}$ that is characteristic of 2D media and the decay rate is enhanced by a factor of up to 90 . 
This result highlights the need to position the emitter away from the graphene to avoid the quenching, and consequently to play with 3D functional tectons. With this aim, several strategies have been developed (Figure 6).

The pyrene unit is known to exhibit van der Waals interactions with $\mathrm{sp}^{2}$-carbon materials and has been used as anchoring point for the non-covalent functionalization of nanotubes. Lopes et al. have used a monopodal singlemolecule magnet consisting of a bis(phthalocyaninato)terbium (III) (TbPc2) complex bearing a pyrenyl group to decorate graphene (Figure 6a).$^{94}$ From the characterizations by Raman spectroscopy, AFM, and electron transport measurements it is inferred that both $\mathrm{TbPc}_{2}$ and graphene electronic properties are intact.

To enhance the stability of the adlayer on the one hand, to position the active functionality away from the graphene substrate and to control the orientation relative to the surface on the other hand, Mann et al. have developed multivalent binding motifs interacting with graphene surface through three "feet" (Figure 6b). ${ }^{95-96}$ The tripodal binding motifs are based on pyrene, phenanthrene or naphthalene binding groups linked to a tetrahedral core functionalized with redoxactive moieties. It was shown by cyclic voltammetry via an analysis of electron-transfer kinetics that these tripods adopt an upright orientation, whereas monopodal molecules tend to lie flat. Moreover, the binding characteristics in terms of stability are governed by the total footprint of the tripod structure.

The importance of this multipodal approach was demonstrated by functionalizing a pyrene-based tripod with an antibody (anti-E. coli antibody) in view of graphene-based biosensors. ${ }^{97}$ The tripod molecule incorporates an $\mathrm{N}$ hydroxysuccinimidyl (NHS) ester to allow the bioconjugation. It was shown that the antibody activity and specificity are retained when immobilized onto this tripodal structure in comparison to the attachment to a monovalent binding group. More recently, the tripodal strategy was applied to graphene oxide (GO) which consists of oxidized hydrophilic regions and graphitic hydrophobic regions. ${ }^{98}$ It is well known that the latter regions disrupt protein structure and quench the emission of fluorophores. To evidence the contribution of the tripodal strategy, the previous tripod which adsorbs on graphitic regions, was biofunctionalized with an enzyme (serine protease enzyme chymotrypsin). It was demonstrated that the enzyme activity is preserved whereas unmodified GO strongly inhibits the enzyme and induces structural changes. More generally, this result shows the interplay of interactions between proteins and the GO surface. In the same way, a fluorescent dye was immobilized onto the tripod without significant fluorescence quenching demonstrating the effective decoupling in the graphitic domains.

\section{d) Controlling the self-assembly of "functional tectons"}

As earlier discussed in the previous section 2., a popular molecular species used for 2D-systems on graphenoid substrates is the phthalocyanine (Pc) and porphyrin (Por) family. Given their ability to form highly-ordered, long range
2D-monolayers ${ }^{99-100}$ a wide range of examples of such systems have been reported with double-decker complexes ${ }^{101}$ alternating single/double Pc systems ${ }^{100}$ and metal-ligand interactions. Up until now, significant research has been developed towards the preparation and analysis of the photophysical properties of Pc/Por and graphene nanostructures, ${ }^{102-104}$ but there is still a lack of significant synthetic developments towards the controllable organization of long-range Pc-graphene arrays and the development of 3Dsurface confined architectures.

A more recently proposed system based on a Janus-tecton strategy was developed by Du et al., transferring the Janus tecton based strategy towards the non-covalent functionalization of graphene. ${ }^{105}$ Having in hand a library of functional 3D tectons (see part 2.2b) they studied the supramolecular self-assembly at a graphene monolayer grown by CVD on a polycrystalline copper foil. It was evidenced by STM at the liquid/solid interface that the tectons form wellordered 2D adlayers incorporating 3D nanostructures. The most important result demonstrated was, that whatever the upper-level functional unit, the lattice parameters remain the same and correspond to the same lattice formed on HOPG. Therefore, Janus tectons can constitute a versatile molecular platform that is able to form surface-confined supramolecular adlayers in which it is possible to simultaneously steer the $2 \mathrm{D}$ self-assembly on graphene and tailor the external interface away from the substrate by introducing a wide variety of functional moieties.

Recently, by using this approach, Le Liepvre et al. demonstrated the first fluorescent supramolecular selfassembly on graphene (figure 7$)^{106}$. To avoid the quenching of fluorescence, a 3D tecton (PTCDI-JT) was designed, where a PTCDI fluorophore is linked to the pedestal by a spacer. The pedestal should prevent the adsorption of PTCDI on graphene on the one hand, and form a tunnelling barrier for electrons expected to suppress the electron-exchange quenching process (Dexter transfer) from the dye to the graphene layer on the other hand. The self-assembly properties of PTCDI-JT on both HOPG and CVD graphene transferred on mica were investigated by STM at the liquid/solid interface at room temperature. A deep analysis, supported by modelling, of the STM images at the liquid/solid interface indicates that PTCDI-JT tectons are self-assembled in a regular manner on graphene. The main result is the recording of a photoluminescence spectrum of the self-assembled PTCDI-JT on graphene, whereas no signal is observed for PTCDI adsorbed on this substrate. Although the fluorescence quantum yield remains still low, maybe due to a residual Förster resonance energy transfer, the authors provide an emissive 'graphene-adlayer' system where the quenching by the optics-friendly substrate is circumvented.

\section{Conclusions}

Within this critical review we have summarized the most representative current strategies used for surface functionalization by supramolecular self-assembly, in view of 
potential exploitation for the fabrication of functional nanodevices (Table 1). We have evidenced that with the surface patterning being well mastered, surface functionalization has emerged as a new frontier for supramolecular self-assembly at surfaces. On usual flat metal surfaces and HOPG, promising results have been obtained either with supported nanoporous networks acting as host nanoarchitectures capable of molecular guest recognition or with up-standing 3D functional build-blocks used as intrinsic objects (e.g. SMMs) or for positioning away the functionality (e.g. rotational motion and decoupling). More recently, a "new" substrate -graphene-, has attracted tremendous attention since its non-covalent functionalization by supramolecular self-assembly represents a way to either control its electronic properties or provide a new functionality. Finally, this review has highlighted the necessity to incorporate complexity in the dimension perpendicular to the surface, regardless of the substrate. However, all approaches require further research before they become a practical approach and offer many challenges in terms of the chemical engineering aspect of the molecular building blocks.

To go ahead, some possible developments may include the following aspects regarding the design of an 'ideal' 3D molecular building block: (1) They self-assemble to give controllable, long-range ordered arrays on large surface areas with minimal/no defects. (2) These molecular units must contain a "functionality" that will give novel electronic, photonic and or chemical properties to the supramolecular system. This functionality should be "independent" and not interact or affect in any way the ordering of the self-assembly. (3) Their functionality is located at an appropriate distance and position to the surface (de-coupled to the surface, preferentially in a perpendicular orientation to the surface). (4) The surface anchoring group must be mechanically stable, electronically transparent. (5) The versatility of the synthetic route should insure that different functional moieties could be incorporated into the 3D molecular building block. Moreover, incorporating such 3D functional tecton as guests into host nanoporous networks should provide a way to enlarge the applications of these systems.

On the other hand, developing strategies to create new functionality from the interactions between the individual components of the self-assembly is another challenge. This can be achieved e.g. by adsorbing simultaneously 3D tectons equipped with different functionalities (e.g. donor and acceptor) or by favouring graphene-tecton interactions.

The possibility to use as substrates, beside graphene, other $2 \mathrm{D}$ materials such as hexagonal boron nitride (h-BN), ${ }^{107-108}$ or transition metal dichalcogenides (e.g. $\mathrm{MoS}_{2}$ ), ${ }^{109}$ should also offer novel opportunities to create functional structures by alternating 2D materials and organic adlayers.

Moreover, in relation to the processing of these materials for device applications, working at liquid-solid interface must be favoured in order to be compatible with techniques such as printed organic electronics.

And lastly, to take advantage of the long range ordered 3D functional tecton positioning, another breakthrough should be the development of strategies for an efficient parallel addressing of all the integrated self-assembly present on the surface instead of the current manipulation of only individual molecules. This is an important issue for spintronics or atomically thin electroluminescent devices.

\section{Acknowledgements}

This research was supported by French National Research Agency (ANR) (grant ANR-13-BS10-0006-project SAMPLE) and by Global Research Laboratory (GRL) through the National Research Foundation of Korea (NRF) funded by the Ministry of Science, ICT \& Future Planning (2016K1A1A2912753).

\section{Notes and references}

1 J. A. Theobald, N. S. Oxtoby, M. A. Phillips, N. R. Champness and P. H. Beton, Nature, 2003, 424, 1029.

2 J. V. Barth, G. Costantini and K. Kern, Nature, 2005, 437, 671.

3 J. S. Foster and J. E. Frommer, Nature, 1988, 333, 542.

4 J. P. Rabe and S. Buchholz, Science, 1991, 253, 424.

5 N. Lin, S. Stepanow, M. Ruben and J. V. Barth, Top. Curr. Chem., 2009, 287, 1.

6 S. Furukawa and S. De Feyter, Top. Curr. Chem., 2009, 287 87.

7 Y. Yang and C. Wang, Chem. Soc. Rev., 2009, 38, 2576.

8 J. A. A. W. Elemans, S. B. Lei and S. De Feyter, Angew. Chem. Int. Ed., 2009, 8, 7298.dfd

9 L. Bartels, Nature Chemistry, 2010, 2, 87.

10 A. G. Slater, P. H. Beton and N. R. Champness, Chem. Sci., 2011, 2, 1440.

11 R. Gutzler, L. Cardenas and F. Rosei, Chem. Sci., 2011, 2, 2290.

12 K. S. Mali, J. Adisoejoso, E. Ghijsens, I. De Cat and S. De Feyter, Acc. Chem. Res., 2012, 45, 1309.

13 X. Bouju, C. Mattioli, G. Franc, A. Pujol and A. Gourdon, Chem. Rev. 2017, 117, 1407.

14 D. Bonifazi, S. Mohnani and A. Llanes-Pallas, Chem. Eur. J., 2009, 15, 7004.

15 T. Kudernac, S. Lei, J. A. A. W. Elemans and S. De Feyter, Chem. Soc. Rev., 2009, 38, 402.

16 J. Adisoejoso, K. Tahara, S. Okuhata, S. Lei, Y. Tobe and S. De Feyter, Angew. Chem., Int. Ed., 2009, 48, 7353

17 S. Stepanow, M. Lingenfelder, A. Dmitriev, H. Spellmann, E. Delvigne, N. Lin, X. Deng, C. Cai, J. V. Barth and K. Kern, Nature Materials, 2004, 3, 229

18 K. Tahara, K. Katayama, M. O. Blunt, K. Iritani, S. De Feyter and Y. Tobe, ACS Nano, 2014, 8, 8683.

19 K. Tahara, K. Nakatani, K. Iritani, S. De Feyter and Y. Tobe, ACS Nano, 2016, 10, 2113.

20 G. Schull, L. Douillard, C. Fiorini-Debuisschert, F. Charra, F. Mathevet, D. Kreher and A. J. Attias, Nano Lett., 2006, 6, 1360.

21 N. Wintjes, D. Bonifazi, F. Cheng, A. Kiebele, M. Stohr, T. Jung, H. Spillmann and F. Diederich, Angew. Chem., Int. Ed., 2007, 46, 4089.

22 M. Stohr, M. Wahl, H. Spillmann, L. H. Gadem and T. A. Jung, Small, 2007, 3, 1336.

23 D. Kühne, F. Klappenberger, W. Krenner, S. Klyatskaya, M. Ruben and J. V. Barth, PNAS, 2010, 107, 21333.

24 S. Furukawa, K. Tahara, F. C. De Schryver, M. Van der Auweraer, Y. Tobe and S. De Feyter, Angew. Chem., Int. Ed., 2007, 46, 2831.

25 D. Bleger, D. Kreher, F. Mathevet, A. J. Attias, G. Schull, A. Huard, L. Douillard, C. Fiorini-Debuischert and F. Charra, Angew. Chem., Int. Ed., 2007, 46, 7404. 
26 J. C. Love, L. A. Estroff, J. K. Kriebel, R. G. Nuzzo and G. M. Whitesides, Chem. Rev. 2005, 105, 1103.

27 C. Vericat, M. E. Vela, G. Benitez, P. Carro and R. C. Salvarezza, Chem. Soc. Rev., 2010, 39, 1805.

28 Stefano Casalini, Carlo Augusto Bortolotti, Francesca Leonardi and Fabio Biscarini, Chem. Soc. Rev., 2017, 46, 40.

29 M. Valasek, M. Lindner and M. Mayor, Beilstein J. Nanotechnol., 2016, 7, 374.

30 M. O. Blunt, J. C. Russel, M. C. Gimenez-Lopez, N. Taleb, X. Lin, M. Schröder, N. R. Champness and P. H. Beton, Nature Chemistry, 2011, 3, 74.

31 E. Kim, "Nanostructures of phthalocyanines and their polymers", Encyclopedia of Nanoscience and Nanotechnology., 2004, Vol 8, pp. 629-689, H. Nalwa Ed. American Scientific Publishers

32 N. Ishikawa, M. Sugita, T. Ishikawa, S.-Y. Koshihara, Y. Kaizu, J. Am. Chem. Soc., 2003, 125, 8694.

33 E. Moreno Pïneda, T. Komeda, K. Katoh, M. Yamashita, M. Ruben, Dalton Trans, 2016, 45, 18417-18433.

34 K. Katoh, H. Isshiki, T. Komeda and M. Yamashita, Chem. Asian J., 2012, 7, 1154.

35 W. Auwärter, D. Écija, F. Klappenberger and J. V. Barth, Nature Chemistry, 2015, 7, 105-118.

36 V. J. Langlais, R. R. Schlittler, H. Tang, A. Gourdon, C. Joachim and J. K. Gimzewski, Phys. Rev. Lett., 1999, 83, 2809.

$37 \mathrm{M}$. Yu, N. Kalashnyk, W. Xu, R. Barattin, Y. Benjalal, E. Laegsgaard, I. Stensgaard, M. Hliva, X. Bouju, A. Gourdon, C. Joachim, F. Besenbacher and T. R. Linderoth, ACS Nano, 2010, 4, 4097.

38 N. Kalashnyk, M. Yu, R. Barattin, Y. Benjalal, M. Hliwa, C. Joachim, E. Lægsgaard, F. Besenbacher, A. Gourdon, X. Bouju and T. R. Linderoth, Chem. Commun., 2014, 50, 10619.

39 M. D. Watson, F. Jäckel, N. Severin, J. P. Rabe and K. Müllen, J. Am. Chem. Soc., 2004, 126, 1402.

40 F. Matino, G. Shull, F. Köhler, S. Gabutti, M. Mayor and R. Berndt, PNAS, 2011, 108, 961.

41 N. L Schneider, F. Matino, G. Schull, S. Gabutti, M. Mayor and R. Berndt, Phys. Rev. B, 2011, 84, 153403.

42 D. Bléger, F.Mathevet, D. Kreher, A.J.Attias,A.Bocheux, S. Latil, L. Douillard, C. Fiorini-Debuisschert, F. Charra, Angew. Chem. Int. Ed., 2011, 50, 6562.

43 P. Du, D. Kreher, F. Mathevet, P. Maldivi, F. Charra and A.-J. Attias, ChemPhysChem, 2015, 16, 3774.

44 P. Du, M. Jaouen, A. Bocheux, C. Bourgogne, V. Bouchiat, D. Kreher, F. Mathevet, C. Fiorini Debuisschert, F. Charra, A.-J. Attias, Angew. Chem. Int. Ed., 2014, 53, 10060.

45 B. Baisch, D. Raffa, U. Jung, O. M. Magnussen, C. Nicolas, J. Lacour, J. Kubitschke and R. Herges, J. Am. Chem. Soc., 2009, $131,442$.

46 F. L. Otte, S. Lemke, C. Schütt, N. R. Krekiehn, U. Jung, O. M. Magnussen and R. Herges, J. Am. Chem. Soc., 2014, 136, 11248.

47 M. Hammerich and R. Herges, J. Org. Chem., 2015, 80, 11233.

48 M. Hammerich, T. Rusch, N. R. Krekiehn, A. Bloedorn, O. M. Magnussen and R. Herges, ChemPhysChem, 2016, 17, 1870.

49 U. Jung, C. Schütt, O. Filinova, J. Kubittschke, R. Herges and O. Magnussen, J. Phys. Chem. C, 2012, 116, 25943.

50 J. Visser, N. Katsonis, J. Vicario, B. L. Feringa, Langmuir 2009, 25, 5980 .

51 M. S. Rodriguez-Morgade, T. Torres, C. Atienza-Castellanos, D. M. Guldi, J. Am. Chem. Soc.2006, 128, 15145.

52 K. S. Novoselov, A. K. Geim, S. V. Morozov, D. Jiang, Y. Zhang, S. V. Dubonos, I. V. Grigirieva and A. A. Firsov, Science, 2004 306, 666 .

53 A. K. Geim and K. S. Novoselov, Nature Materials, 2007, 6, 183.
54 F. Bonaccorso, Z. Sun, T. Hasan and A. C. Ferrari, Nature Photonics, 2010, 4, 611.

55 S. Niyogi, E. Bekyarova, M. E. Itkis, H. Zhang, K. Shepperd, J. Hicks, M. Sprinkle, C. Berger, C. N. Lau, W. A. de Heer, E. H. Conrad and R. C. Haddon, Nano Lett., 2010, 10, 4061.

56 V. Georgakilas, M. Otyepka, A. B. Bourlinos, V. Chandra, N. Kim, K. C. Kemp, P. Hobza, R. Zboril and K. S. Kim, Chem. Rev. 2012, 112, 6156.

57 V. Georgakilas, J. N. Tiwari, K. C. Kemp, J. A. Perman, A. B. Bourlinos, K. S. Kim and R. Zboril, Chem. Rev. 2016, 116, 5464.

58 H. Y. Mao, Y. H. Lu, J. D. Lin, S. Zhong, A. T. S. Wee and W. Chen, Progress in Surface Science, 2013, 88, 132.

59 W. Chen, S. Chen, D. C. Qi, X. Y. Gao and A. T. S. Wee, J. Am. Chem. Soc., 2007, 129, 10418.

60 T. Hu and I. C. Gerber, J. Phys. Chem. C, 2013, 117, 2411.

61 C. Casiraghi, S. Pisana, K. S. Novoselov, A. K. Geim and A. C. Ferrari, Appl. Phys. Lett., 2007, 91, 233108.

62 C. Coletti, C. Riedl, D. S. Lee, B. Krauss, L. Patthey, K. von Klitzing, J. H. Smet and U. Strake, Phys. Rev. B, 2010, 81, 235401.

63 S. A. Paniagua, J. Baltazar, H. Sojoudi, S. K. Mohapatra, S. Zhang, C. Henderson, S. Graham, S. Barlow and S. Marder, Mater. Horiz., 2014, 1, 111.

64 W. Xu, L. Wang, Y. Liu, S. Thomas, H.-K. Seo, K.-I. Kim, K. S. Kim and T.-W. Lee, Adv Mater., 2015, 27, 1619.

65 P. Lauffer, K. V. Emtsev, R. Graupner, T. Seyller and L. Ley, Phys. Stat. Sol. B, 2008, 245, 2064.

$66 \mathrm{H}$. Huang, S. Chen, X. Gao, W. Chen, and A. T. S. Wee, ACS Nano, 2009, 3, 3431.

67 J. Mao, H. Zhang, Y. Jiang, Y. Pan, M. Gao, W. Xiao and H.-J. Gao, J. Am. Chem. Soc., 2009, 131, 14136.

68 H. Zhang, J. Sun, T. Low, L. Z. Zhang, Y. Pan, Q. Liu, J. H. Mao, H. T. Zhou, H. M. Guo, S. X. Du, F. Guinea and H.-J. Gao, Phys. Rev. B, 2011, 84, 245436.

69 K. Yang, W. D. Xiao, Y. H. Jiang, H. G. Zhang, L. W. Liu, J. H. Mao, H. T. Zhou, S. X. Du and H.-J. Gao, J. Phys. Chem.C, 2012, 116, 14052.

70 S. K. Hämäläinen, M. Stepanova, R. Drost, P. Liljeroth, J. Lahtinen and J. Sainio, J. Phys. Chem.C, 2012, 116, 20433.

71 Y. Ogawa, T. Niu, S. L. Wong, M. Tsuji, A. T. S. Wee, W. Chen and H. Ago, J. Phys. Chem.C, 2013, 117, 21849.

72 P. Järvinen, S. K. Hämäläinen, K. Banerjee, P. Häkkinen, M. ljäs, A. Harju and P. Liljeroth, Nano Lett., 2013, 13, 3199.

73 H. Zhou, J. Mao, G. Li, Y. Wang, X. Feng, S. Du, K. Mullen and H.J. Gao, Appl. Phys. Lett., 2011, 99, 153101.

74 J. Cho, J. Smerdon, L. Gao, Ö. Süzer, J. R. Guest and P. Guisinger, Nano Lett., 2012, 12, 3018.

75 C. Chen, H. Zhang, A. Mills, J. R. Heflin and C. Tao, Scientific Reports, 2015, 5, 14336.

76 S. Barja, M. Garnica, J. J. Hinarejos, A. L. Vazquez de Parga, N. Martin and R. Miranda, Chem. Comm., 2010, 46, 8198.

77 A. Kumar, K. Banerjee, P. Liljeroth, 2016, arXiv: $1611.02462 \mathrm{v} 1$

78 H. Zhang, W. D. Xiao, J. Mao, H. Zhou, G. Li, Y. Zhang, L. Liu, S. Du and H.-J. Gao, J. Phys. Chem. C., 2012, 116, 11091.

79 J. Lu, P. S. E. Yeo, Y. Zheng, Z. Yang, Q. Bao, C. K. Gan and K. P. Loh, ACS Nano, 2012, 6, 944.

80 A. J. Pollard, E. W. Perkins, N. A. Smith, A. Saywell, G. Goretzki, A. G. Phillips, S. P. Argent, H. Sachdev, F. Müller, S. Hüfner, S. Gsell, M. Fischer, M. Schreck, J. Osterwalder, T. Greber, S. Berner, N. R. Champness and P. H. Beton, Angew Chem. Int. Ed., 2010, 49, 1794.

81 Q. H. Wang and M. C. Hersam, Nature Chemistry, 2009, 1 206.

$82^{1}$ K. Banerjee, A. Kumar, F. F. Canova, S. Kezilebieke, A. S. Foster and P. Liljeroth, J. Phys. Chem. C, 2006, 120, 8722. 
83 B. Li, K. Tahara, J. Adisoejoso, W. Vanderlinden, K. S. Mali, S. De Gendt, Y. Tobe and S. De Feyter, ACS Nano, 2013, 7, 10764.

84 J. M. MacLeod and F. Rosei, Small, 2014, 10, 1038.

85 K. S. Mali, J. Greenwood, J. Adisoejoso, R. Phillipson and S. De Feyter, Nanoscale, 2015, 7, 1566.

86 A. Ciesielski and P. Samori, Adv. Mater., 2016, 28, 6030.

87 M. C. Prado, R. Nascimento, L. G. Moura, M. J. S. Matos, M. S. C. Mazzaoni, L. G. Cancado, H. Chacham and B. R. A. Neves, ACS Nano, 2011, 5, 394.

88 B. Li, A. V. Klekachev, M. Cantoro, C. Huyghebaert, A. Stesmans, I. Assselberghs, S. De Gendt and S. De Feyter, Nanoscale, 2013, 5, 9640.

89 X. Zhang, E. H. Huisman, M. Gurram, W. R. Browne, B. J. van Wees and B. L. Feringa, Small, 2014, 10, 1735.

90 H. Yang, A. J. Mayne, G. Comtet, G. Dujardin, Y. Kuk, P. Sonnet, L. Stauffer, S. Nagarajan and A. Gourdon, Phys. Chem. Chem. Phys., 2013, 15, 4939.

91 N. V. Kozhemyakina, J. M. Englert, G. Yang, E. Spiecker, C. D. Schmidt, F. Hauke and A. Hirsch, Adv. Mater., 2010, 22, 5483.

92 A. Wojcik and P. V. Kamat, ACS Nano, 2010, 11, 6697.

93 L. Gaudreau, K. J. Tielrooij, G. E. D. K. Prawiroatmodjo, J. Osmond, F. J. Garcia de Abajo and F. H. L. Koppens, Nano Lett., 2013, 13, 2030.

94 M. Lopes, A. Candini, M. Urdampillete, A. Reserbat-Plantey, V. Bellini, S. Klyatskaya, L. Marty, M. Ruben, M. Affronte, W. Wernsdorfer and N. Bendiab, ACS Nano, 2010, 4, 7531.

95 J. A. Mann, J. Rodriguez-Lopez, H. D. Abruna and W. R. Dichtel, J. Am. Chem. Soc., 2011, 133, 17614.

96 J. A. Mann and W. R. Dichtel, ACS Nano, 2013, 7, 7193.

97 J. A. Mann, T. Alava, H. G. Craighead and W. R. Dichtel, Angew. Chem. Int. Ed., 2013, 52, 3177.

98 C. Sun, K. L. Wlaker, D. L. Wakefield and W. R. Dichtel, Chem. Mater., 2015, 27, 4499.

99 X. Qiu, C. Wang, Q. Zeng, B. Xu, S. Yin, H. Wang, S. Xu, C. Bai, J. Am. Chem. Soc. 2000, 122, 5550.

100 A. S. Klymchenko, J. Sleven, K. Binnemans, S. De Feyter, Langmuir 2006, 22, 723.

101 J. Gomez-Segura, I. Diez-Perez, N. Ishikawa, M. Nakano, J. Veciana, D. Ruiz-Molina, Chem. Commun.2006, 2866.

102 T. Takami, D. P. Arnold, A. V. Fuchs, G. D. Will, R. Goh, E. R. Waclawik, J. M. Bell, P. S. Weiss, K. Sugiura, W. Liu, J. Jiang, J. Phys. Chem. B, 2006, 110, 1661.

103 G. Bottari, G. de la Torre, T. Torres, Acc. Chem Res, 2015, 48, 900-910.

104 Auwärter, D. Écija, Klappenberger, J. Barth, Nature Chemistry, 2015, 7, 105-118.

105 P. Du, M. Jaouen, A. Bocheux, C. Bourgogne, Z. Han, V. Bouchiat, D. Kreher, F. Mathevet, C. Fiorini-Debuisschert, F. Charra and A.-J. Attias, Angew. Chem. Int. Ed., 2014, 53, 10060.

106 S. Le Liepvre, P. Du, D. Kreher, F. Mathevet, A.-J. Attias, C. Fiorini-Debuisschert, L. Douillard and Fabrice Charra, ACS Photonics, 2016, 3, 2291.

107 F. Schulz, R. Drost, S. K. Hämäläinen and P. Liljeroth, ACS Nano, 2013, 7, 11121.

108 S. Joshi, F. Bischoff, R. Koitz, D. Ecija, K. Seufert, A. P. Seitsonen, J. Hutter, K. Diller, J. I. Urgel, H. Sachdev, J. V. Barth and W. Auwärter, ACS Nano, 2014, 8, 430.

109 N. Afsharimani, A. Minoia, C. Volcke, M. Surin, R. Lazzaroni, J. Y. Balandier, C. Niebel, Y. H. Geerts and B. Nysten, J. Phys. Chem. C 2013, 117, 21743. 


\section{Materials Horizons}

\section{Minireview}

Beyond "decorative" 2D supramolecular self-assembly: strategies towards functional surfaces for Nanotechnology

Lydia Sosa-Vargas, Eunkyoung Kim, and André-Jean Attias*

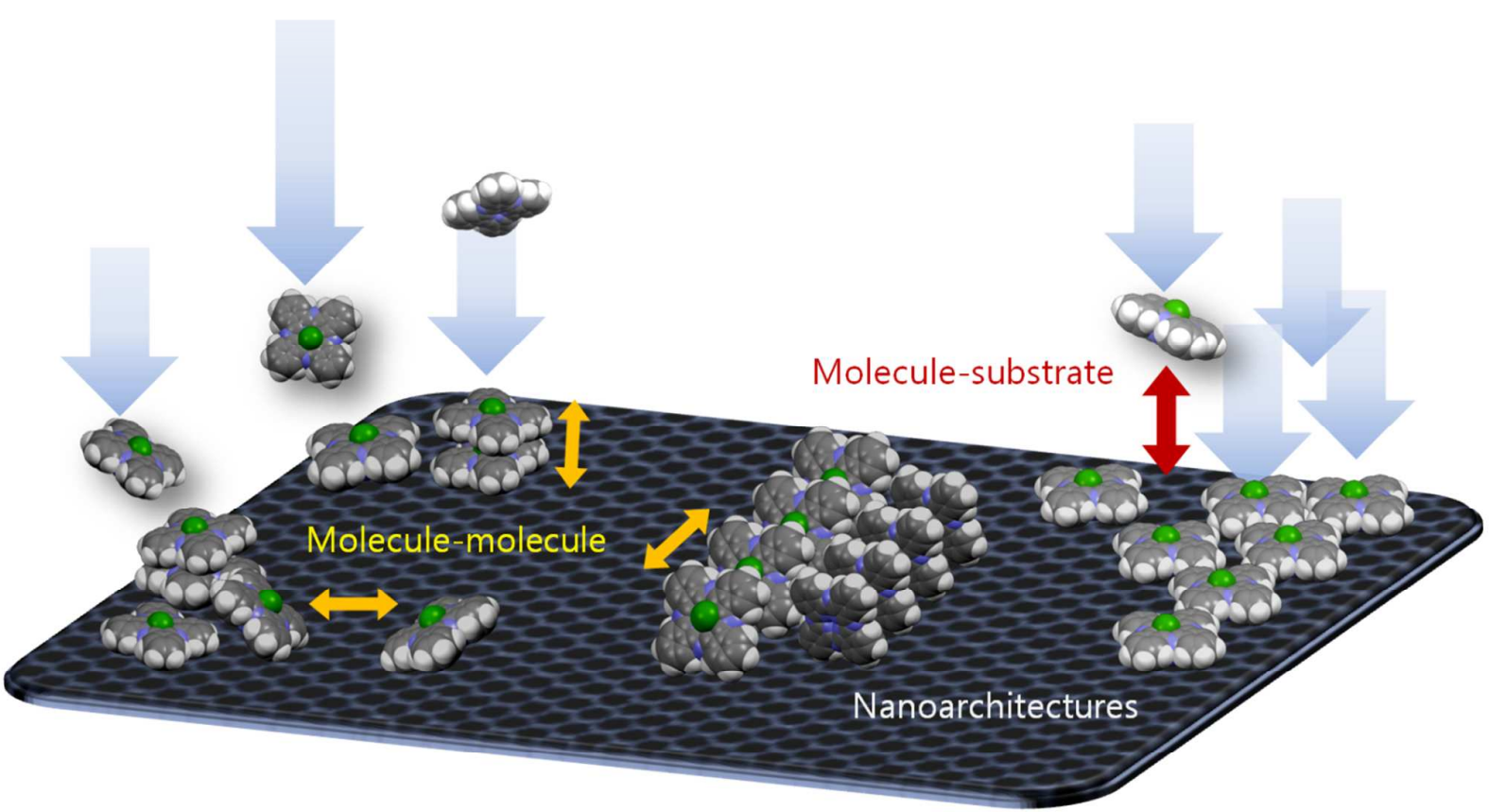

Fig. 1 Supramolecular self-assembly process on a substrate. Orientation and aggregation of the adsorbed species relies on the degree of interaction between molecular units (molecule-molecule) and with the surface (molecule-substrate), forming nanoarchitectures, which can be further tuned by either structural modification of the molecule or self-assembling procedures. 


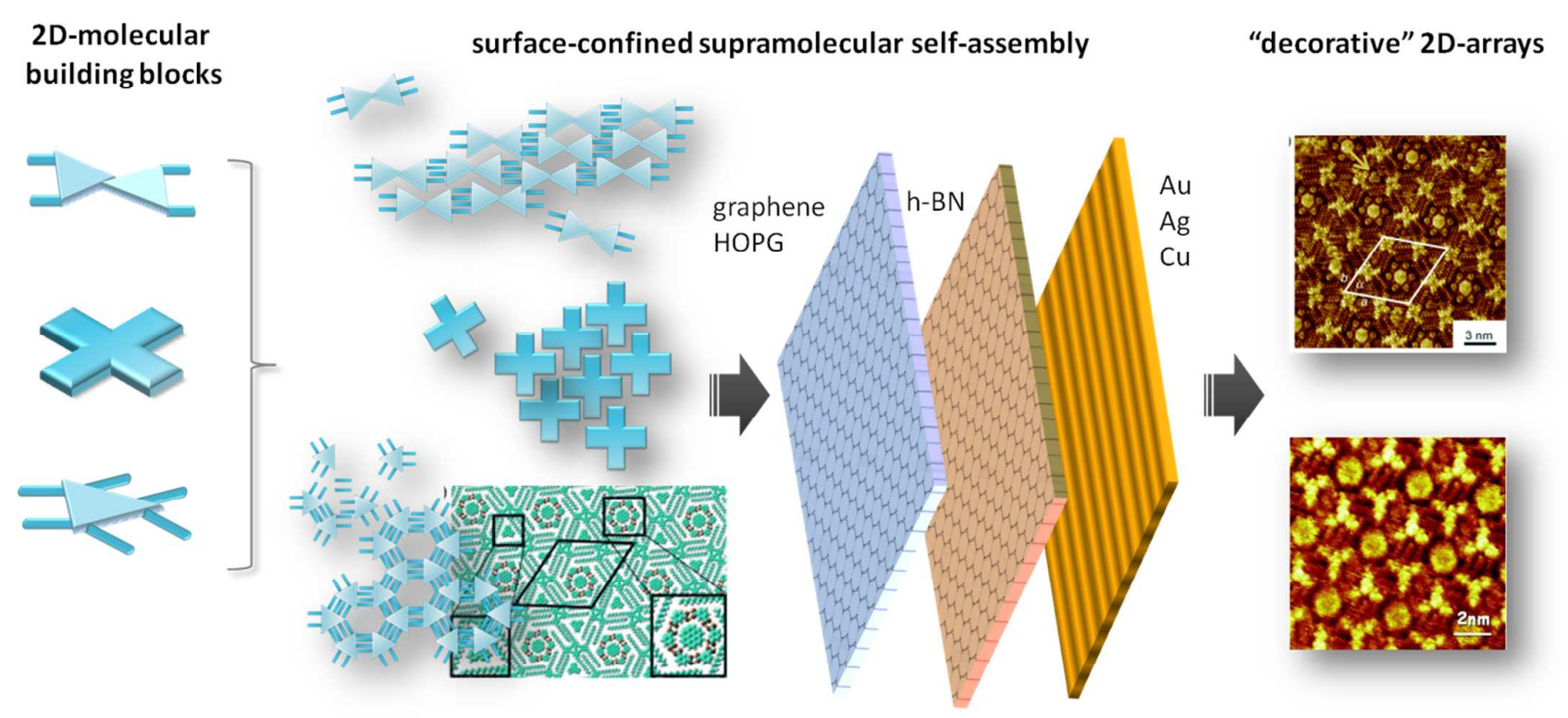

Fig. 2 General overview of the current strategies developed towards surface-confined self-assemblies of 2D building blocks. The molecular tectons can be finely-tuned to form a wide variety of motifs and patterns in varying degrees of complexity, and be tailored with a specific substrate in mind. The STM image of multicomponent nanoporous network (top-right) and the schematic molecular model showing the Kagome structure of the same system (middle-bottom) is adapted from ref 16, whereas the STM image (bottom right) of a host-guest system is from ref.21. 

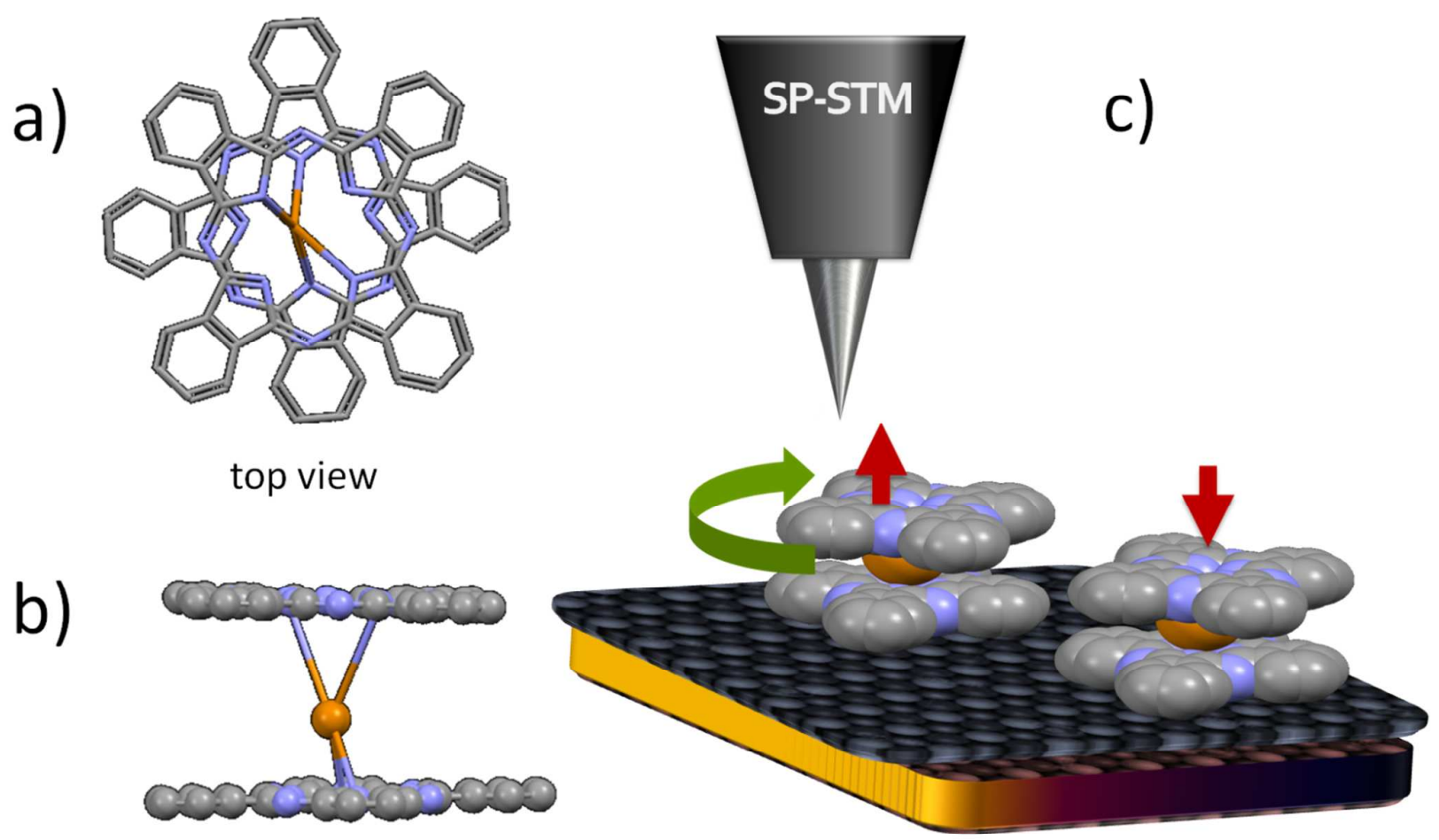

side view

Fig. 3 Molecular structure of a double-decker lanthanide phthalocyanine complex $\left(\mathrm{LaPc}_{2}\right)$, where the top and bottom Pc macrocycles are in a staggered conformation (a). These types of structures not only provide a convenient way of projecting into the third-dimension (b) but can also display a functionality as single-molecule magnets when a stimulus is provided (c). 


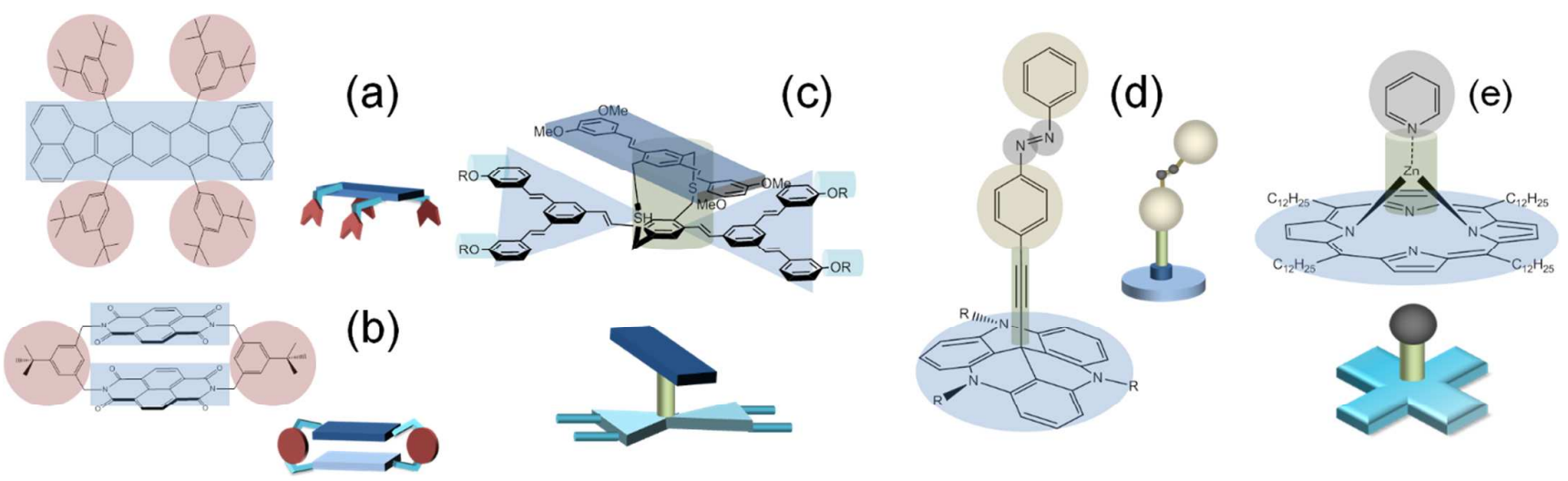

Fig. 4 Examples of 3D-tectons that permit decoupling from metal substrate: molecular landers (a), cyclophane-type molecules (b), a Janus tecton (c), the TATA-based platform (d), and coordinated Zn-porphyrin (e). 


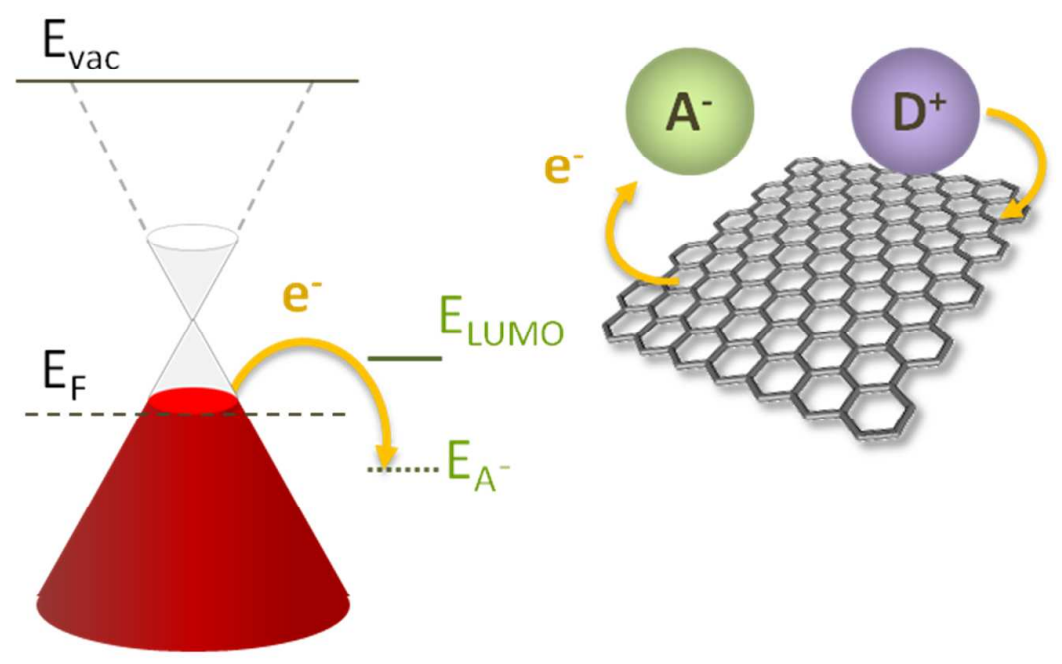

p-doping
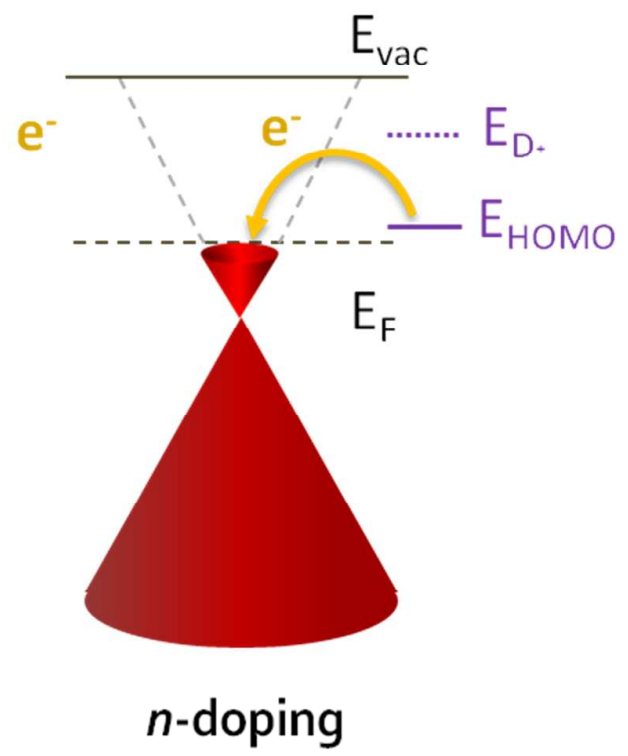

Fig. 5 Schematic of the p-type (left) and n-type (right) doping of graphene by means of electron donor (D)or acceptor (A) molecules. (adapted from Ref. 60). 

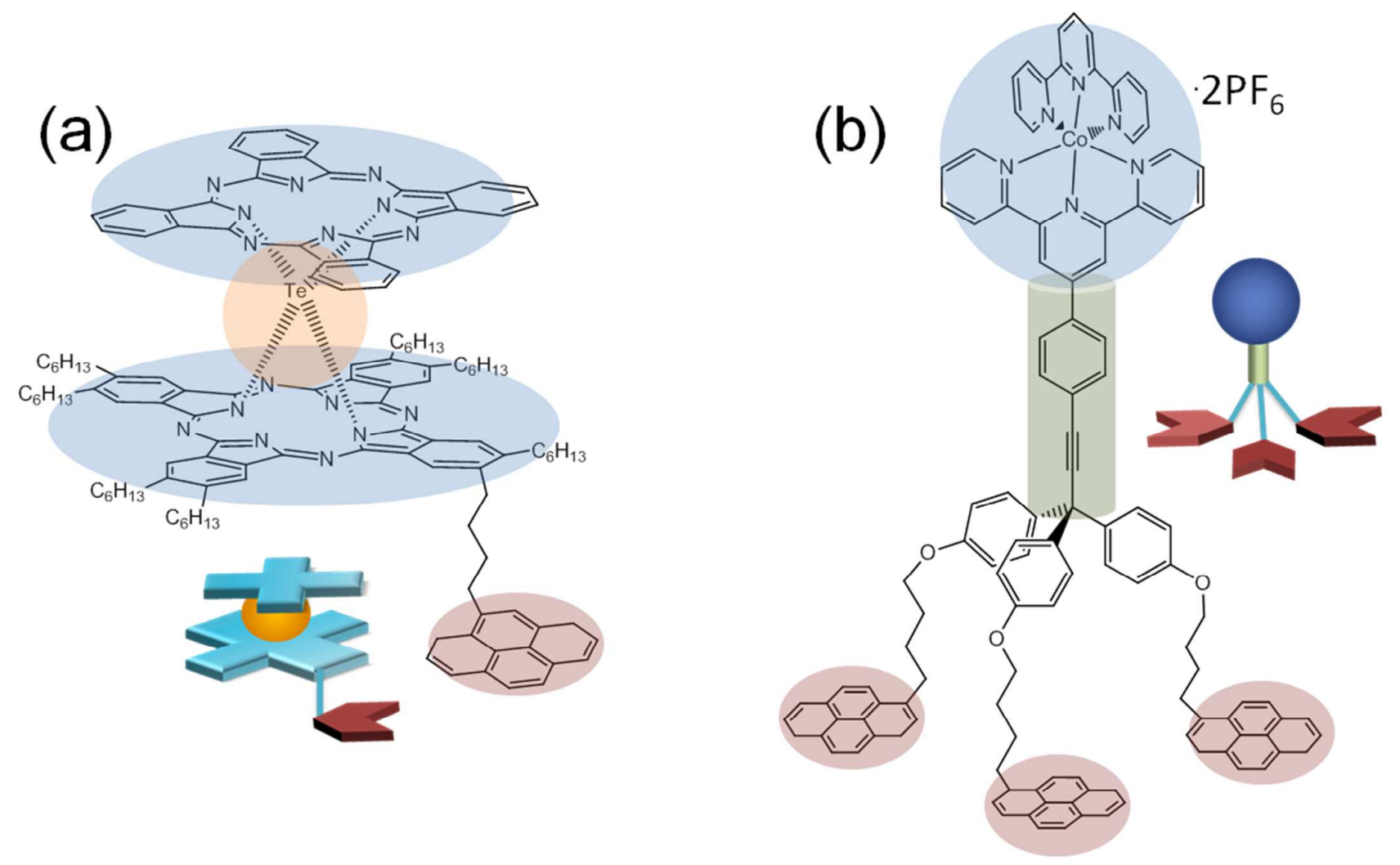

Fig. 6 Examples of molecules with an off-plane functionality that can be adsorbed on graphenoid surfaces: a monopodal SMM (a), a tripodal structure (b). 


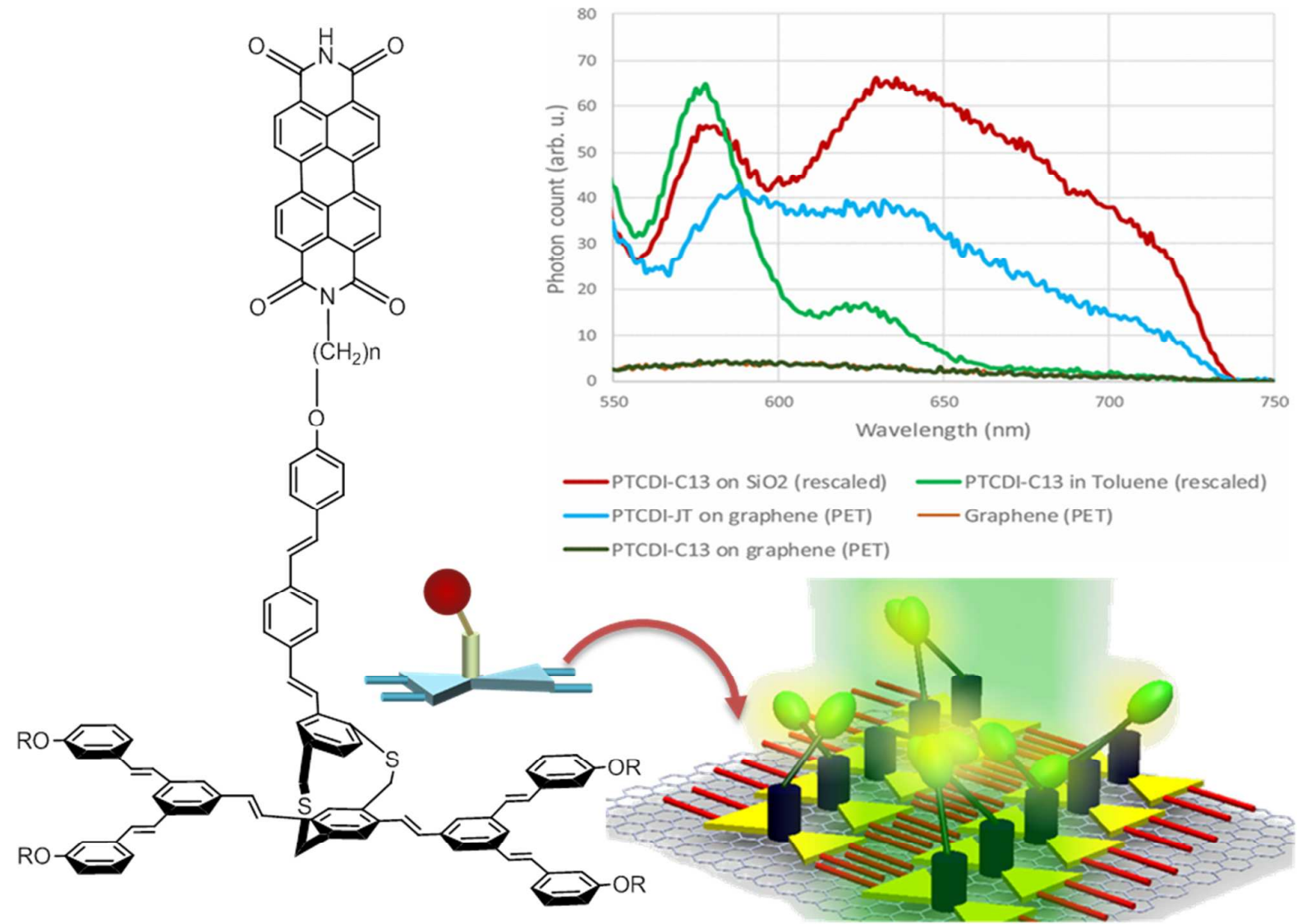

Fig. 7 Fluorescent supramolecular self-assembly on graphene. The quenching of the fluorescence of the adsorbed dye (PTCDI) by graphene is hindered at the molecular scale, through a specifically designed 3D-Janus tecton (PTCDI-JT). The photoluminescence spectrum of self-assembly on graphene (blue) is compared with PTCDI-C13 reference signals in toluene (green), self-assembled on graphene (black), and in the microcrystal solid state (red). (excitation wavelength at $532 \mathrm{~nm}$ ). (adapted from ref.106) 
Table 1. Examples of 3D functional tectons that form supramolecular self-assembly into long-range 2D-arrays: main features, current applications, and future developments

\begin{tabular}{|c|c|c|c|c|c|c|}
\hline \multirow[b]{2}{*}{$\begin{array}{l}\text { Molecular } \\
\text { unit }\end{array}$} & \multirow[b]{2}{*}{ Structure } & \multirow[b]{2}{*}{ Substrate } & \multirow[b]{2}{*}{$\begin{array}{l}\text { Deposition } \\
\text { method }\end{array}$} & \multirow[b]{2}{*}{$\begin{array}{l}\text { Applications } \\
\text { reported in the } \\
\text { literature }\end{array}$} & \multicolumn{2}{|c|}{ Future developments } \\
\hline & & & & & $\begin{array}{l}\text { Functional } \\
\text { guest in } \\
\text { nanoporous } \\
\text { networks } \\
\end{array}$ & $\begin{array}{l}\text { Integration into } \\
\text { devices }\end{array}$ \\
\hline $\begin{array}{l}\text { Sandwich or } \\
\text { multidecker } \\
\text { Pc/Por } \\
\text { (Ref. 28-31) }\end{array}$ & & $\begin{array}{c}\mathrm{Au}(111) \\
\mathrm{Cu}(111) \\
\text { HOPG } \\
\text { Graphene }\end{array}$ & $\begin{array}{l}\text { Thermal } \\
\text { evaporation, } \\
\text { Self-assembly at } \\
\text { solid-liquid } \\
\text { interface, UHV }\end{array}$ & $\begin{array}{l}\text { Single-molecule (SM) } \\
\text { magnets, } \\
\text { rotors, } \\
\text { electroluminescence }\end{array}$ & $\checkmark$ & $\begin{array}{c}\text { Data storage } \\
\text { Electroluminescent } \\
\text { devices }\end{array}$ \\
\hline $\begin{array}{l}\text { Pc/Por } \\
\text { platform } \\
\text { (Ref. 46) }\end{array}$ & & HOPG & $\begin{array}{l}\text { Self-assembly at } \\
\text { solid-liquid } \\
\text { interface }\end{array}$ & - & $\checkmark$ & $\begin{array}{l}\text { Functionality on } \\
\text { demand }\end{array}$ \\
\hline $\begin{array}{c}\text { Janus tecton } \\
\text { (Ref. 40, } \\
\text { 105-106) }\end{array}$ & & $\begin{array}{c}\text { HOPG } \\
\text { Graphene }\end{array}$ & $\begin{array}{l}\text { Self-assembly at } \\
\text { solid-liquid } \\
\text { interface }\end{array}$ & $\begin{array}{c}\text { Photonics } \\
\text { (luminescence) }\end{array}$ & $x$ & $\begin{array}{c}\text { Electroluminescent } \\
\text { devices }\end{array}$ \\
\hline $\begin{array}{c}\text { TATA } \\
\text { platform } \\
\text { (Ref. 45-49) }\end{array}$ & & $\mathrm{Au}(111)$ & $\begin{array}{l}\text { self-assembly at } \\
\text { solid-liquid } \\
\text { interface } \\
\text { (immersion) }\end{array}$ & $\begin{array}{c}\text { Photonics } \\
\text { (photoswitching) }\end{array}$ & $x$ & $\begin{array}{c}\text { Photoswitching } \\
\text { devices }\end{array}$ \\
\hline
\end{tabular}

